\title{
Article
}

\section{A Generalized Bivariate Copula for Flood Analysis in Peninsular Malaysia}

\author{
Izzat Fakhruddin Kamaruzaman ${ }^{1,2, *}$, Wan Zawiah Wan Zin ${ }^{1}$ and Noratiqah Mohd Ariff ${ }^{1}$ \\ 1 School of Mathematical Sciences, Faculty of Science and Technology, Universiti Kebangsaan Malaysia, \\ 43600 Bangi, Selangor, Malaysia \\ 2 Faculty of Business, Multimedia University, Jalan Ayer Keroh Lama, 75450 Bukit Beruang, Melaka, \\ Malaysia \\ * Correspondence: izzat.kamaruzaman@mmu.edu.my; Tel.: +60-176211210
}

\begin{abstract}
This study generalized the best copula to characterize the joint probability distribution between rainfall severity and duration in Peninsular Malaysia using two dimensional copulas. Specifically, to construct copulas, Inference Function for Margins (IFM) and Canonical Maximum Likelihood (CML) methods were specially exploited. For the purpose of achieving copula fitting, the derived rainfall variables by making use of the Standardized Precipitation Index (SPI) were fitted into several distributions. Five copulas, namely Gaussian, Clayton, Frank, Joe and Gumbel were put to the tests to establish the best data fitted copula. The tests produced acknowledged and satisfactory results of copula fitting for rainfall severity and duration. Surveying the Akaike Information Criterion (AIC) and the Bayesian Information Criterion (BIC), only three copulas produced a better fit for parametric and semi parametric approaches. Finally, two consistency tests were conducted and the results had shown that Frank Copula produced consistent results.
\end{abstract}

Keywords: Archimedean Copula; Elliptical Copula; Multivariate Distribution; Hydrology

\section{Introduction}

Flood; as an overflow of a huge amount of water beyond its normal limits has never failed to challenge water resource management researchers. Natural disaster that is quite difficult to understand its features has flushed away a lot of money and is regarded as one of the most catastrophic natural disasters. These frequent climatic phenomena since past civilization still haunt current civilization nowadays because it very much impacts on the economic, environmental and social sectors. In Malaysia, it is the main meteorological disaster, while other disasters occur less frequently. In monetary terms, a typical flood costs RM1.2 billion in 2012 [1], more than damages incurred due to other disasters. As a measure of hydrological flood mitigation, it is undoubtedly very crucial to at a first place determine the probabilistic characteristics of rainfalls. Therefore, there are many ongoing investigations for hydrological floods quantitative estimation by considering future climate changes.

Severity, intensity, depth, and duration are major characteristics of rainfalls in hydrologic design and floodplain management. They are normally employed when designing certain water supply systems. As rainfall characteristics are haphazard in nature, the suitable technique to discover rainfalls usually use probabilistic theories. Researchers among others, Renard and Lang [2]; Zhang and Singh [3]; Abdul Rauf and Zeephongsekul [4]; Daneshkhah et al. [5]; and Ozga-Zielinski et al. [6] evaluated the analyses of those characteristics. Probabilistic analysis approach of rainfalls is either univariate or multivariate. Univariate rainfall characteristic analysis has been widely used by most researchers since its inception due to the results of the study of encouraging.

Hydrologic events whether flood or drought, are considered multivariate events after taking into accounts some of the variables associated with them. Only a handful of researchers deliberately 
choose multivariate analysis of hydrologic events over low and inadequate data factors, complex mathematical treatments, and the very limited number of available models. On the other hand, a bivariate distribution is considered as a more common and easier method to explain the correlated hydrologic variables. However, there are some disadvantages for these bivariate distributions; one of them is that the same family is required for each marginal distribution.

To curb such situations, multivariate distribution construction, making use of copulas, may come in handy. Speaking of copulas, they are functions which merge univariate distribution functions, generating multivariate distribution functions. Due to the fact that they are fit for the purposes, may researchers in insurance and finance have extensively employed them to model the dependence structure and joint probability distributions since their initiation by Sklar [7]. The popularity and application of copulas in hydrology has rapidly dispersed as copulas are efficient for illustrating and describing the dependencies among multiple hydrologic variables [2,3,5,8-12].

Firstly, rainfalls are multivariate and they ought to be characterized by dependent random variables. As a result, univariate analyses are not fitting the purposes as expressively stated by Shiau [13]; Genest et al. [14]; and Genest et al. [15]. Secondly, in fact, traditional bivariate distributions required marginal distributions to be of the same family and this has complicated their solutions. The consequence, the number of available models has becoming limited. Thirdly, copulas act as functions that link other multivariate distribution functions to univariate distributions. They are also able to model the dependence structure among random variables autonomously of the marginal distributions. Lastly, copulas for continuous random variables are excellent in fabricating a multivariate distribution with any given different univariate distribution family and eventually could correspond to a suitable dependence structure among component random variables. The relationship between dependent random variables for given univariate marginal distributions had been reduced as a result of the sophisticated joint distribution modelling.

Copulas are majorly exploited to model the dependence structure between two or more variables, for example, precipitation and soil moisture [16], or flood peak and volume [17]. There are varieties of copula families, established and available to be exercised to model all kinds of different dependence structures [18-20]. Kelly and Krzysztofowicz [21] made use of Meta-Gaussian Distribution in hydrology field in which it was among the pioneers, taking into account different marginal distributions that came with different covariance structures in bivariate frequency analysis. Shiau [13] in the study constructed a joint drought duration and severity distribution, made the most of the bivariate Ali-Mikhail-Haq, Clayton, Farlie-Gumbel-Morgenstern, Frank, Galambos, Gumbel-Hougaard and Plackett Copulas. The copula-based joint probabilities and return periods for drought duration and severity were seemed to meet empirical values prerequisites. Shiau et al. [22] applied the Clayton copula using the exponential distribution for drought duration and the gamma distribution for drought severity. Another researcher; Wong [23], applied trivariate Gaussian and Gumbel Copulas to fit rainfall that came out with results that the data were characterized way far better by Gumbel Copula utilizing three parameter marginal Weibull distributions. To test on peak flows from a watershed in the framework of combined risk in Quebec, Canada, Favre et al. [24] had also developed a methodology for representing extreme values using copulas in which they have tested four copulas types. In their respective study, to harvest reliable results, they also modelled peak flows and volumes using three copulas.

Thus, the current author through this study believed that it was important to derive bivariate rainfall distribution using the copula method. As a result, four Archimedean Copulas and one Elliptical Copula were scrutinized and evaluated for comparisons. The authors also has opted a semi parametric method to estimate the joint distribution of rainfall characteristics due to its robustness. The main reason of implementing this approach is the marginal distributions that are frequently used belong to specific parametric families and their adoption could lead to spurious inferences if the underlying assumptions were violated.

Prior to copula fitting, the Standardized Precipitation Index (SPI), developed by Mckee et al. [25], is employed to defined floods. Each flood event is characterized by firstly fitted rainfall duration and severity, separately using probability distributions. Later on univariate marginal 
distributions were linked by certain copulas to create the joint distribution of rainfall duration and severity. The monthly rainfall series of 48 stations in Peninsular Malaysia were used as an example to exemplify the proposed methodology.

\section{Materials and Methods}

\subsection{Study Area and Data}

The field of research was solely focused on the Peninsular Malaysia located in the Northern latitude zone between 1 and $6^{\circ} \mathrm{N}$ and the Eastern longitude from 100 to $103^{\circ} \mathrm{E}$. Regarding the weather in Peninsular Malaysia, it is generally hot and humid throughout the year. The level of temperatures and rainfall is strongly influenced by winds which blow from the Indian Ocean, also known as Southwest Monsoon Wind, blowing from May to September, and from the South China Sea which is the Northeast Monsoon Wind that blows from November to March. The transitional period between the two monsoon events that occur in March until April, and September until October is known as the intermonsoon period which brings constant rainfalls to almost all areas of the peninsula. The annual rainfall is eventually tabulated to be $80 \%$ per year, ranging from $2000 \mathrm{~mm}$ to $2500 \mathrm{~mm}$.

As to make a statistical modelling, the author has taken into account and reviewed 51 years records of data during the years 1965-2015. These data involved 48 rainfall stations and they have been obtained with collaboration with the Department of Irrigation and Drainage Malaysia (DID). The study over a long period time of data was in line with the intention of the author who wanted the most accurate results of the rainfall patterns in Malaysia [26]. Furthermore, the longer the data period, the more useful the study was, especially as the credibility of the frequency estimator is closely related to the size of the sample during the analysis process happened later on [27]. All 48 intentionally selected rainfall stations were flood prone areas in Peninsular Malaysia (refer to Figure 1) [28].

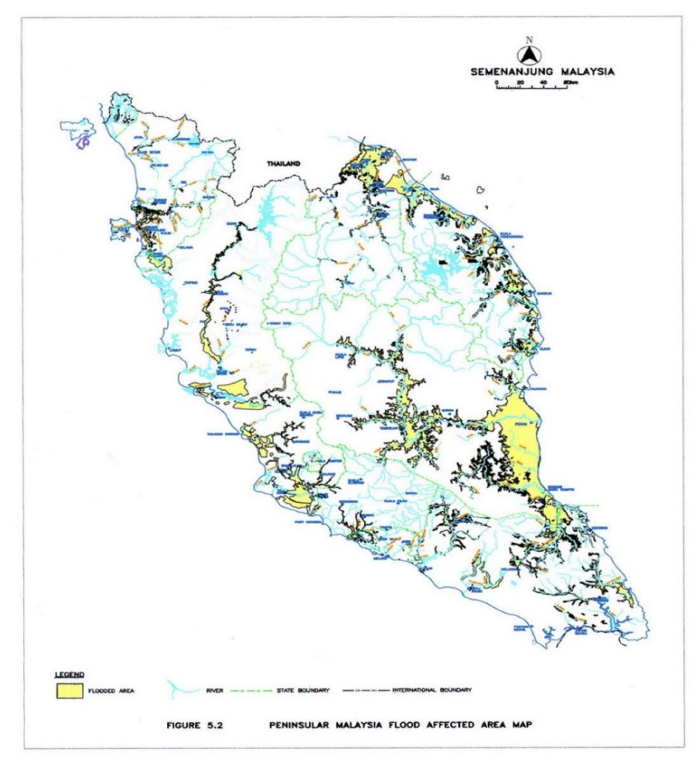

Figure 1. Peninsular Malaysia flood affected area map Source: Department of Irrigation and Drainage Malaysia

\subsection{Standard Precipitation Index}

The Standardized Precipitation Index (SPI) was introduced by Mckee et al. [25] for the purpose of determining and monitoring the drought occurring in places or areas. The SPI calculation method 
4 of 21

is based on the long-term rainfall series for a specific period such as 1, 3, 6 and 12 months. The first procedure to calculate the SPI is fitting the long-term rainfall record to a probability distribution. Once the probability distribution is successfully determined, the cumulative probability of observed rainfall is calculated and then inverse transformed by a standard normal distribution with zero mean and variance equal to one. The resulting quantile is the SPI that is intended to be determined. Guttman [29] has detailed the way it calculates the process. SPI can be also be used to measure rainfall deficits in terms of probability, for multiple time scales. If the SPI is positive then the observed rainfall is greater than the median, whereas if the SPI is negative, then it is below the median. The wet and dry conditions were classified according to SPI scales and they were listed in Table 1. Mckee et al. [25] defined the flood as a period in which the SPI kept becoming positive and achieved a value of 1.0 or more.

In this study, the data at first went through a transformation into indices in the manner as described above and were subsequently exercised to compute the rainfall severity as represented by

$$
S=\sum_{i=1}^{d} S P I_{i}
$$

where $i$ is the month and $d$ is the duration of rainfall.

Table 1. Standard Precipitation Index (SPI) Classification

\begin{tabular}{cc}
\hline SPI & Classification \\
\hline$\geq 2$ & Extremely wet \\
1.5 to 1.99 & Very wet \\
1.0 to 1.49 & Moderately wet \\
-0.99 to 0.99 & Near normal \\
-1.0 to -1.49 & Moderately dry \\
-1.5 to -1.99 & Severely dry \\
$\leq-2$ & Extremely dry \\
\hline
\end{tabular}

\subsection{Marginal Distribution}

Determining the appropriate marginal distribution for each rainfall characteristic is one of the most important procedures in fitting copulas. The author in this research had considered two rainfall characteristics namely rainfall severity and duration. The distribution functions tested in this study are the Gamma, Log normal, Exponential, Weibull and Log Logistic distributions. As studied and acknowledged by Boulanger et al. [30], there was zero consistency in distribution that had made it suitable for all areas, seasons and climates. Below are the equations of the probability density functions of the five distributions and also their domains:

1. Gamma distribution

$$
f(x)=\frac{1}{\Gamma(\alpha) \beta^{\alpha}} e^{-\frac{x}{\beta}} x^{\alpha-1}, \quad x>0
$$

where $\alpha$ is the scale parameter and $\beta$ the shape parameter.

2. Log Normal distribution

$$
f(x)=\frac{1}{x \sigma \sqrt{2 \pi}} e^{-\frac{(\ln x-\mu)^{2}}{2 \sigma^{2}}}, \quad x>0
$$

where $\mu$ and $\sigma$ are the mean and standard deviation of $\ln (X)$ respectively. 
3. Weibull distribution

$$
f(x)=\left(\frac{\alpha}{\beta}\right)\left(\frac{x}{\beta}\right)^{(\alpha-1)} e^{-\left(\frac{x}{\beta}\right)^{\alpha}}, \quad x>0
$$

where $\alpha$ is the shape parameter and $\beta$ the scale parameter.

4. Exponential distribution

$$
f(x)=\lambda e^{-\lambda x}, \quad x>0
$$

where $\lambda$ is the rate parameter.

5. Log Logistic distribution

$$
f(x)=\frac{\alpha}{\beta}\left(\frac{x}{\beta}\right)^{\alpha-1}\left(1+\left(\frac{x}{\beta}\right)^{\alpha}\right)^{-2}, \quad x>0
$$

where $\alpha$ is the shape parameter and $\beta$ the scale parameter.

The Maximum Likelihood Estimation (MLE) method is the standard method used to estimate the parameters of these marginal distributions. The best fitted distribution can be determined based on the smallest AIC value.

\subsection{Copula Theory}

A copula is a powerful multivariate function describing dependence of variables transformed by their margins, which can simplify inference procedures of multivariate distributions and studies on hydrological dependence. Considering continuous random vector as $(X, Y)$ with marginal distributions $F_{X}(x)$ and $F_{Y}(y)$, the joint distribution function can be articulated with its marginal distributions and copula function $C$ [19] as stated below:

$$
P(X \leq x, Y \leq y)=C\left(F_{X}(x), F_{Y}(y) ; \theta\right)=C(u, v ; \theta)
$$

where $\theta$ is the copula's parameter; $u$ and $v$ are realizations of the random variables $U=F_{X}(x)$ and $V=F_{Y}(y)$. The density function of $C$ is specified as:

$$
c(u, v ; \theta)=\frac{d^{2} C(u, v ; \theta)}{d u d v}
$$

The two-dimensional copula $C$ maps the two marginal distributions into the joint distribution as $(0,1)^{2} \rightarrow(0,1)$. The value of $\theta$ can be estimated either by IFM or CML.

\subsection{Types of Copula}

\subsubsection{Elliptical Copula}

Copulas associated to elliptical distributions are very useful in real world applications since they have some properties of the multivariate normal distribution. The most commonly used and familiar Elliptical Copulas are the multivariate Gaussian Copula and the multivariate Student Copula. 


\subsubsection{Archimedean Copula}

The Archimedean Copula is one of the most opted copula functions by researchers as the measures computation of dependence has been simplified for use. Archimedean Copulas can be defined by the generator $\varphi($.$) , a continuous strictly decreasing function from [0,1]$ to $[0, \infty)$ such that $\varphi(1)=0$. If $\varphi^{-1}($.$) represents the inverse function of \varphi($.$) , the Archimedean copula is$ defined by the equation below:

$$
C(u, v)=\varphi^{-1}(\varphi(u)+\varphi(v))
$$

Archimedean Copulas works with many different generators and they can be observed in Table 4.1 of Nelsen [19]. In general, $\varphi$ is dependent on a parameter $\theta$ and it therefore be symbolized by $\varphi_{\theta}$.

In this study, four types of Archimedean copula; the Clayton, Frank, Joe and Gumbel together with one elliptical copula, namely Gaussian were employed to model dependence patterns of different hydrological variables. Table 2 depicts that different choices of generator yield several important bivariate families of copulas.

Table 2. Families of bivariate copulas

\begin{tabular}{cccc}
\hline $\begin{array}{c}\text { Family of } \\
\text { Copulas }\end{array}$ & Copulas & $C_{\theta}(u, v)$ & Parameter Space \\
\hline $\begin{array}{c}\text { Elliptical } \\
\text { Archimedean }\end{array}$ & $\begin{array}{c}\text { Gaussian } \\
\text { Clayton }\end{array}$ & $\Phi_{\Sigma}\left(\Phi^{-1}(u), \Phi^{-1}(v)\right)$ & $-1 \leq \theta \leq 1$ \\
& Frank & $\left(u^{-\theta}+v^{-\theta}-1\right)^{-1 / \theta}$ & $0 \leq \theta<\infty$ \\
& & $-\theta^{-1} \log \left(1+\frac{\left(e^{-\theta u}-1\right)\left(e^{-\theta v}-1\right)}{e^{-\theta}-1}\right)$ & $-\infty \leq \theta<\infty$ \\
& Joe & $1-\left[(1-u)^{\theta}+(1-v)^{\theta}-(1-u)^{\theta}(1-v)^{\theta}\right]^{1 / \theta}$ & $1 \leq \theta<\infty$ \\
& Gumbel & $\exp \left[-\left((-\log (u))^{\theta}+(-\log (v))^{\theta}\right)^{1 / \theta}\right]$ & $1 \leq \theta<\infty$ \\
& & &
\end{tabular}

\subsection{Estimating Copula Parameters}

Once the copula has been selected, the parameter of copulas has to be estimated. As part of the study, the parameters estimation of some of the most common copulas was thoroughly described. There are primarily two methods of doing this; a fully parametric method and a semi parametric method. The first method was the inference functions for margins (IFM) method by Joe [18], which relied on parametric univariate marginal distributions assumption. First the parameters of the margins are estimated and then each parametric margin is plugged into the copula likelihood. This full likelihood is maximized with respect to the copula parameters. However, to make this method a huge success, finding appropriate parametric models for the margins is a must. It might not be easy and straightforward particularly if they demonstrate an evidence of heavy tails or skewness. On the other hand, interestingly, even without parametric assumptions for the margins, the author can plug the univariate empirical cumulative distribution functions into the likelihood to yield a semi parametric method. This method signifies the pseudo-likelihood [31] or canonical maximum likelihood (CML) method and in which it has been described in Genest et al. [32]. 


\subsection{Goodness of Fit Test}

The appropriate probability distribution can be determined by Akaike Information Criterion (AIC) and Bayesian Information Criterion (BIC). The lowest AIC and BIC values indicate that the tested model were approaching the actual model. AIC and BIC are expressed as:

Given the observe value $u_{i, j}, i=1, \ldots, N, j=1,2$, AIC and BIC for bivariate copula $C$ with parameter $\theta$ can be expressed as:

$$
A I C=-2 \sum_{i=1}^{N} \ln \left[c\left(u_{i, 1}, u_{i, 2} \mid \theta\right)\right]+2
$$

and

$$
B I C=-2 \sum_{i=1}^{N} \ln \left[c\left(u_{i, 1}, u_{i, 2} \mid \theta\right)\right]+\ln (N)
$$

\section{Results}

The monthly SPI for Kuala Brang station starting from year 1965 until 2015 can be seen in Figure 2. This station is the wettest area in Peninsular Malaysia with the highest annual mean rainfall of $3737.11 \mathrm{~mm}$. Referring to the graph, it is apparent that Kuala Brang regularly faces very wet event once every five to 10 years with the SPI index exceeding 2.0 in about 13 extremely wet events during these years.

\section{KUALA_BRANG}

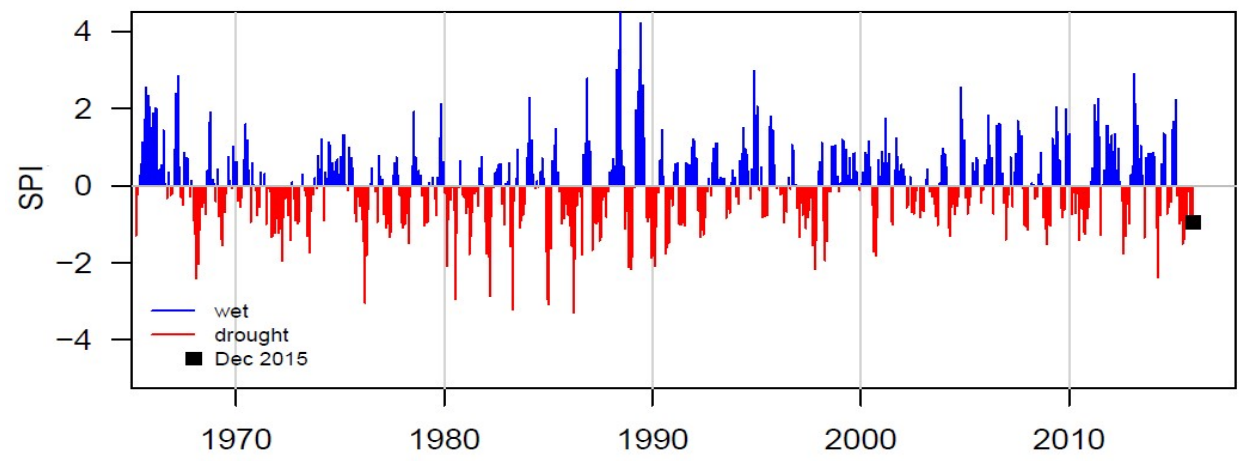

Figure 2. The monthly SPI of Kuala Brang station (1965-2015)

All parameters for the five marginal distributions used are estimated from the data sets using the method of MLE. For each station, the best fitted distribution for severity and duration is subsequently selected using the AIC. The one with the lowest AIC value indicated the best fitted marginal distribution. Based on the obtained results from the study of all stations, Log Logistic distribution was best to be used for examining rainfall severity, while rainfall duration was best fitted by a Weibull distribution. Table 3 thoroughly illustrated the best fitted distribution for severity and duration of each station.

Table 3. The best fitted distribution for severity and duration

\begin{tabular}{llllll}
\hline Station & Severity & Duration & Station & Severity & Duration \\
\hline Meranti & Llogis & Weibull & Kota Tinggi & Lnorm & Weibull \\
Kuala Jambu & Llogis & Weibull & Sembrong & Llogis & Weibull \\
Stesen Keretapi Tumpat & Lnorm & Weibull & Ladang Lambak & Llogis & Llogis \\
Kampung Ibok & Llogis & Llogis & Yong Peng & Weibull & Weibull \\
Dungun & Weibull & Weibull & Ladang Ulu Paloh & Llogis & Weibull \\
Kuala Brang & Lnorm & Gamma & Jementah & Lnorm & Gamma \\
Kuala Telemong & Weibull & Weibull & Segamat & Weibull & Weibull \\
\hline
\end{tabular}




\begin{tabular}{llllll}
\hline Marang & Weibull & Weibull & Empangan Labong & Llogis & Weibull \\
Kuala Terengganu & Llogis & Weibull & Pusat Pertanian Endau & Llogis & Weibull \\
Kampung Rahmat & Weibull & Weibull & Stor Jps Endau & Lnorm & Weibull \\
Banggol & Exp & Weibull & Parit Nibong & Llogis & Weibull \\
Setiu & Lnorm & Weibull & Rantau Panjang & Lnorm & Llogis \\
Pelangi Kampung Jawi 2 & Llogis & Weibull & Jeniang & Weibull & Weibull \\
Bentong & Llogis & Llogis & Telok Rimba & Llogis & Weibull \\
Paya Membang & Weibull & Weibull & Jasin & Lnorm & Gamma \\
Kampung Serambi & Gamma & Weibull & Jalan Empat & Llogis & Llogis \\
Kerdau & Weibull & Weibull & Ladang Bukit Bertam & Gamma & Weibull \\
Sanggang & Weibull & Weibull & Batu Kurau & Llogis & Weibull \\
Pekan & Llogis & Weibull & Ladang Sepang & Lnorm & Weibull \\
Penor & Llogis & Weibull & Sungai Mangg & Llogis & Weibull \\
Kuala Krau & Weibull & Weibull & Ladang Bukit Kerayong & Llogis & Weibull \\
Paya Kangsar & Weibull & Weibull & Ladang Tuan Mee & Weibull & Weibull \\
Ladang Kuala Reman & Llogis & Weibull & Tanjung Karang & Lnorm & Weibull \\
Kuala Lipis & Llogis & Weibull & Sungai Bernam & Lnorm & Weibull \\
\hline
\end{tabular}

Prior to fitting the copulas, examining the dependence structure between two rainfall characteristics was an important aspect by computing the Kendall's tau measure of concordance. The values of these measures were between 0.75 and 0.88 which were statistically significant positive correlation. For each of the five copulas selected, estimation of the parameter $\theta$ using the IFM and CML methods together with their goodness of fit tests results are displayed in Table A1 and Table A2 respectively (refer to appendix). The best model selected for each case was the one with the lowest AIC and BIC values. In Table A1, Gaussian Copula is the commonly selected and the best copula to characterize the association between rainfall severity and duration. While in Table A2, Frank copula have shown a dominant result. The locations of the copulas for chosen stations in Peninsular Malaysia for IFM and CML methods respectively were shown in Figure 3 (a) and Figure $3(b)$.

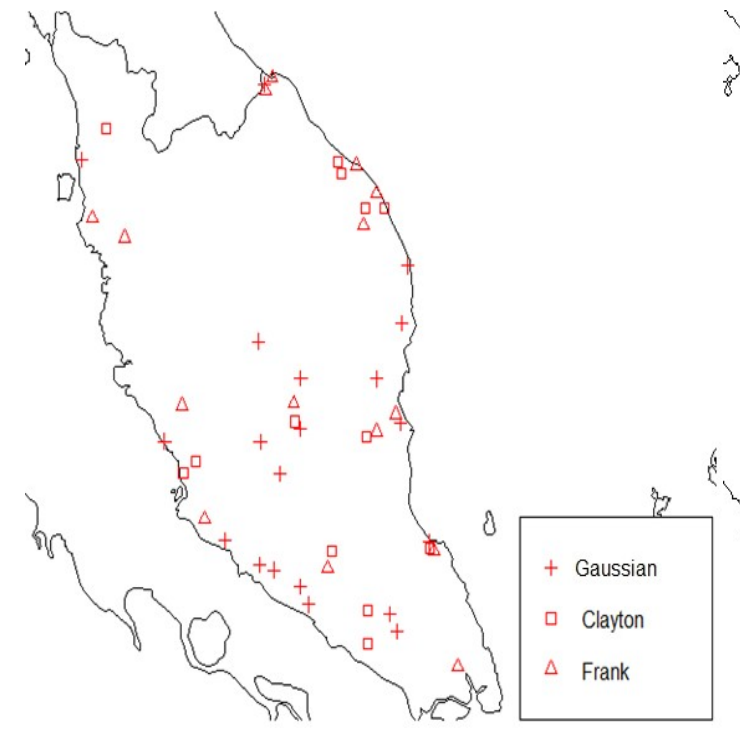

(a)

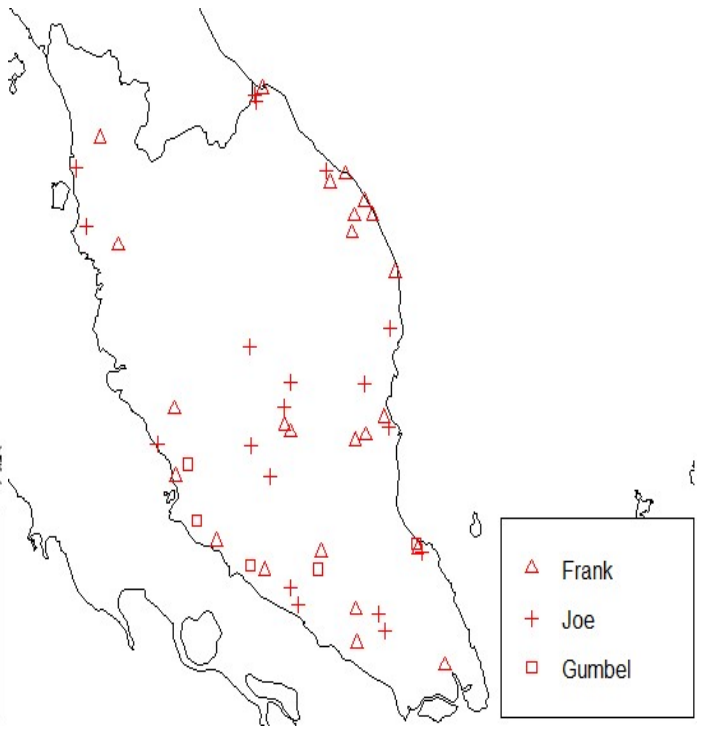

(b)

Figure 3. (a) Location of copulas for each station by using IFM; (b) Location of copulas for each station by using CML

The results as stated in Table A1 and Table A2 indicated that only three copulas were suitable to be representing the association between rainfall severity and duration in Peninsular Malaysia. They were Gaussian, Clayton and Frank for a parametric method; and Frank, Joe and Gumbel for a semi 
parametric method. To arrive at the final stage, two consistency tests were later on conducted, namely Interquartile Range (IQR) and standard deviation (SD). The authors found that Frank Copula was perfect and appropriate to be used as a generalized method for analysing flood in Peninsular Malaysia as it produced the smallest IQR and SD values which is the desired values. Significant information and data statistics were specified in Table 4 and Table 5 to be referred.

Table 4. Consistency tests results for parametric copula

\begin{tabular}{lcccc}
\hline Copula & \multicolumn{2}{c}{ IQR } & \multicolumn{2}{c}{ SD } \\
\hline & AIC & BIC & AIC & BIC \\
Gaussian & 23.48 & 23.45 & 17.98 & 17.95 \\
Clayton & 29.65 & 29.46 & 21.69 & 21.64 \\
Frank & 20.68 & 20.49 & 17.20 & 17.14 \\
\hline
\end{tabular}

Table 5. Consistency tests results for semi parametric copula

\begin{tabular}{lcccc}
\hline Copula & \multicolumn{2}{c}{ IQR } & \multicolumn{2}{c}{ SD } \\
\hline & AIC & BIC & AIC & BIC \\
Frank & 11.88 & 11.94 & 10.18 & 10.14 \\
Joe & 22.85 & 23.04 & 15.48 & 15.50 \\
Gumbel & 16.69 & 16.76 & 11.01 & 11.02 \\
\hline
\end{tabular}

\section{Discussion and Conclusions}

When it comes to understanding the global water cycle and climatic phenomena, researchers cannot take investigating the interdependence of hydrologic and climatic variables for granted. Hence, researchers have extensively exploited copulas as it can be witnessed in many statistical literatures for constructing joint distributions in an effort to model the suitable dependence structure of these variables. There are a few multivariate copulas that are perfectly model the rainfall data including the Archimedean and Elliptical Copulas. These two copulas have been presented and evaluated above.

The Archimedean Copula family comes with a large variety of copulas, but they can be constructed easily. Either the correlation amongst hydrologic variables is positive or negative; many copulas of this kind can be applied without hassles. Due to this reasons it has become a choice when performing hydrologic analyses. The implementation of these properties has been stated by Genest \& Mackay [33] and Favre et al. [24] in their studies. Using four Archimedean Copulas to rainfall bivariate analysis, only the Frank Copula had been proven to be more proper for the analysis of both IFM and CML approaches. This was a result of Frank Copula's ability to maintain the consistency of the results, compared to other copulas. Also, Frank Copula can be exercised as a generalized method.

Instead, the elliptical copulas offer substantial practical interests as they can simply be applied in dimensions, even if they were more than two; and they were comprised of a generalized classical multivariate normal distribution. Daneshkhah et al. [5] cited in their study that Elliptical Copula modelled the dependencies of the flood variables for parametric approach more accurately, even though it was not for the semi parametric. Hence, Gaussian Copula performed very well for IFM method, but not for CML.

Particularly in hydrologic studies that deal with a variety of cases in which the modelling of multivariate hydrologic variables is of particular interest. For that reason, this study presented the models that implied important implications and would be beneficial for many areas of water resources and hydrologic systems.

Author Contributions: All authors made equal contribution to this paper.

Funding: This research received no external funding. 
Acknowledgments: The authors sincerely acknowledge the Department of Irrigation and Drainage Malaysia (DID), for providing the daily precipitation data that been used in this study. The work is financed by MyBrain15 Scholarship provided by the Ministry of Higher Education of Malaysia.

Conflicts of Interest: The authors declare no conflict of interest.

\section{Appendix A}

Table A1. Goodness of Fit tests for IFM

\begin{tabular}{|c|c|c|c|c|c|}
\hline Station & Copula & Estimate $\theta$ & $\begin{array}{l}\text { Maximum } \\
\text { Likelihood }\end{array}$ & AIC & BIC \\
\hline \multirow[t]{5}{*}{ Meranti } & Gaussian & 0.95 & 56.38 & -110.77 & -108.86 \\
\hline & Clayton & 6.47 & 55.48 & -108.96 & -107.05 \\
\hline & Frank ${ }^{*}$ & 20.07 & 56.41 & -110.81 & -108.90 \\
\hline & Joe & 4.44 & 39.12 & -76.23 & -74.32 \\
\hline & Gumbel & 4.26 & 50.01 & -98.02 & -96.11 \\
\hline \multirow[t]{5}{*}{ Kuala Jambu } & Gaussian* & 0.96 & 48.90 & -95.79 & -94.08 \\
\hline & Clayton & 5.16 & 39.80 & -77.59 & -75.88 \\
\hline & Frank & 18.80 & 44.41 & -86.82 & -85.11 \\
\hline & Joe & 5.83 & 40.28 & -78.55 & -76.84 \\
\hline & Gumbel & 4.87 & 46.81 & -91.62 & -89.91 \\
\hline \multirow[t]{5}{*}{ Stesen Keretapi Tumpat } & Gaussian & 0.95 & 52.05 & -102.10 & -100.25 \\
\hline & Clayton & 4.68 & 41.29 & -80.58 & -78.73 \\
\hline & Frank ${ }^{*}$ & 19.51 & 53.30 & -104.59 & -102.74 \\
\hline & Joe & 4.47 & 36.53 & -71.06 & -69.21 \\
\hline & Gumbel & 4.03 & 45.52 & -89.03 & -87.18 \\
\hline \multirow[t]{5}{*}{ Kampung Ibok } & Gaussian* & 0.97 & 64.23 & -126.46 & -124.63 \\
\hline & Clayton & 8.32 & 58.47 & -114.94 & -113.11 \\
\hline & Frank & 25.24 & 61.57 & -121.14 & -119.31 \\
\hline & Joe & 6.27 & 49.41 & -96.82 & -94.99 \\
\hline & Gumbel & 5.59 & 59.97 & -117.94 & -116.11 \\
\hline \multirow[t]{5}{*}{ Dungun } & Gaussian* & 0.97 & 64.81 & -127.63 & -125.74 \\
\hline & Clayton & 7.60 & 55.90 & -109.80 & -107.90 \\
\hline & Frank & 24.08 & 60.31 & -118.61 & -116.72 \\
\hline & Joe & 6.40 & 49.59 & -97.19 & -95.30 \\
\hline & Gumbel & 5.55 & 59.89 & -117.77 & -115.88 \\
\hline \multirow[t]{5}{*}{ Kuala Brang } & Gaussian & 0.93 & 43.21 & -84.43 & -82.69 \\
\hline & Clayton & 5.27 & 41.43 & -80.86 & -79.13 \\
\hline & Frank* & 18.06 & 44.05 & -86.09 & -84.35 \\
\hline & Joe & 4.00 & 27.55 & -53.10 & -51.36 \\
\hline & Gumbel & 3.72 & 36.61 & -71.21 & -69.48 \\
\hline \multirow[t]{5}{*}{ Kuala Telemong } & Gaussian & 0.95 & 57.64 & -113.28 & -111.31 \\
\hline & Clayton* & 8.66 & 71.17 & -140.34 & -138.37 \\
\hline & Frank & 24.38 & 67.49 & -132.99 & -131.02 \\
\hline & Joe & 3.47 & 31.15 & -60.30 & -58.33 \\
\hline & Gumbel & 3.70 & 44.01 & -86.03 & -84.06 \\
\hline \multirow[t]{4}{*}{ Marang } & Gaussian & 0.95 & 62.85 & -123.70 & -121.71 \\
\hline & Clayton* & 6.93 & 64.66 & -127.32 & -125.33 \\
\hline & Frank & 19.44 & 59.75 & -117.49 & -115.51 \\
\hline & Joe & 4.20 & 41.32 & -80.65 & -78.66 \\
\hline
\end{tabular}


6 of 21

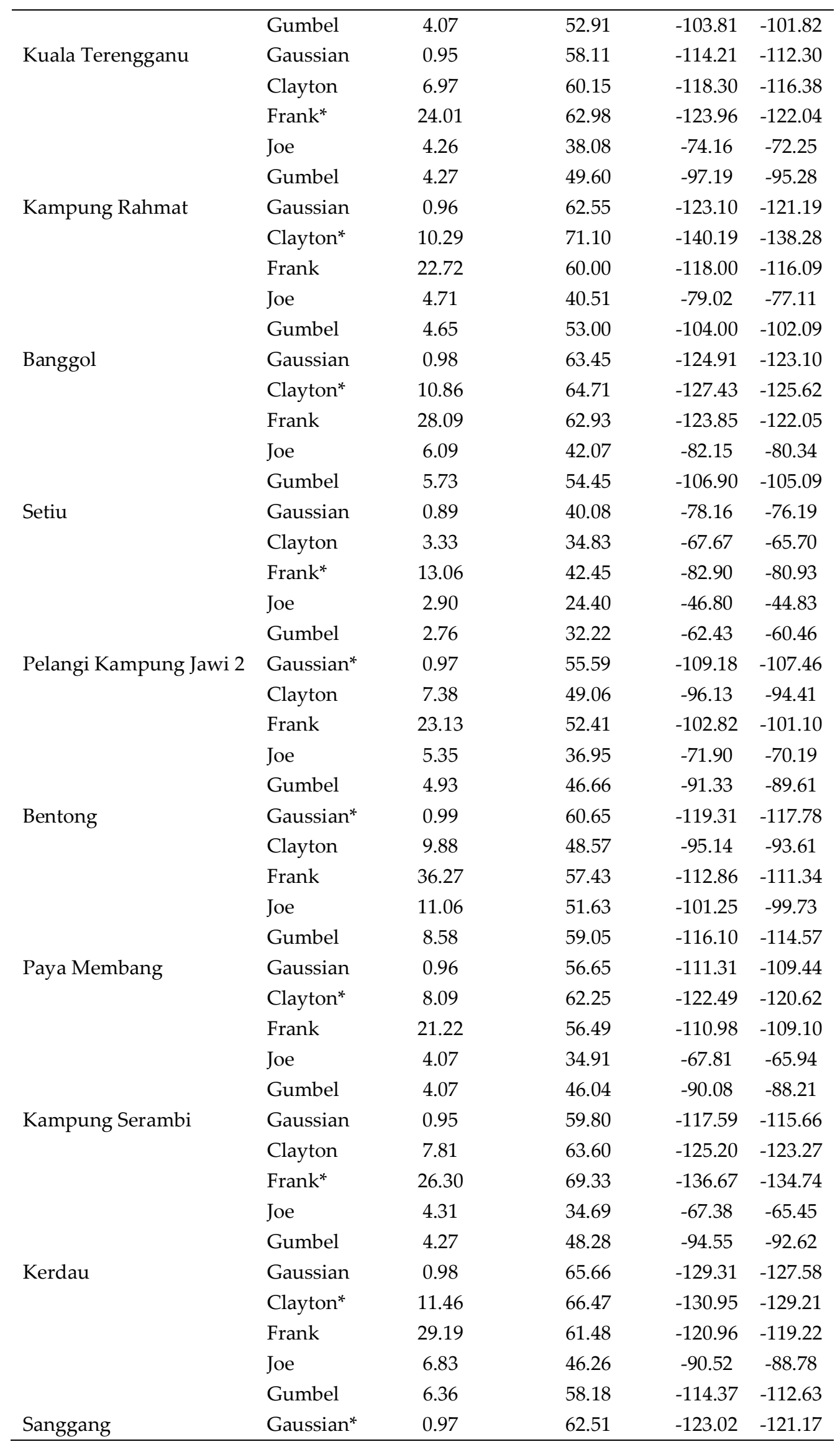




\begin{tabular}{|c|c|c|c|c|c|}
\hline & Clayton & 7.84 & 58.38 & -114.76 & -112.91 \\
\hline & Frank & 23.26 & 58.85 & -115.70 & -113.85 \\
\hline \multirow{5}{*}{ Pekan } & Joe & 5.55 & 43.41 & -84.82 & -82.97 \\
\hline & Gumbel & 5.08 & 54.59 & -107.18 & -105.33 \\
\hline & Gaussian* & 0.95 & 55.32 & -108.64 & -106.77 \\
\hline & Clayton & 4.93 & 45.29 & -88.58 & -86.71 \\
\hline & Frank & 18.18 & 50.25 & -98.50 & -96.63 \\
\hline \multirow{5}{*}{ Penor } & Joe & 5.44 & 45.59 & -89.17 & -87.30 \\
\hline & Gumbel & 4.62 & 52.86 & -103.72 & -101.85 \\
\hline & Gaussian & 0.95 & 50.33 & -98.66 & -96.81 \\
\hline & Clayton & 7.20 & 55.30 & -108.60 & -106.75 \\
\hline & Frank ${ }^{*}$ & 22.11 & 56.50 & -111.00 & -109.15 \\
\hline \multirow{5}{*}{ Kuala Krau } & Joe & 3.58 & 28.77 & -55.53 & -53.68 \\
\hline & Gumbel & 3.72 & 39.51 & -77.03 & -75.18 \\
\hline & Gaussian & 0.97 & 67.23 & -132.47 & -130.54 \\
\hline & Clayton & 8.33 & 66.98 & -131.97 & -130.04 \\
\hline & Frank* & 26.54 & 70.41 & -138.81 & -136.88 \\
\hline \multirow{5}{*}{ Paya Kangsar } & Joe & 4.51 & 39.27 & -76.54 & -74.61 \\
\hline & Gumbel & 4.58 & 52.94 & -103.88 & -101.95 \\
\hline & Gaussian* & 0.99 & 73.79 & -145.58 & -143.82 \\
\hline & Clayton & 14.11 & 72.10 & -142.20 & -140.44 \\
\hline & Frank & 37.63 & 72.39 & -142.78 & -141.02 \\
\hline \multirow{5}{*}{ Ladang Kuala Reman } & Joe & 7.98 & 50.42 & -98.84 & -97.08 \\
\hline & Gumbel & 7.28 & 63.99 & -125.98 & -124.22 \\
\hline & Gaussian* & 0.95 & 43.45 & -84.90 & -83.21 \\
\hline & Clayton & 5.68 & 38.91 & -75.82 & -74.13 \\
\hline & Frank & 18.12 & 41.91 & -81.83 & -80.14 \\
\hline \multirow{5}{*}{ Kuala Lipis } & Joe & 4.10 & 28.60 & -55.21 & -53.52 \\
\hline & Gumbel & 3.91 & 36.51 & -71.01 & -69.32 \\
\hline & Gaussian* & 0.97 & 53.03 & -104.05 & -102.39 \\
\hline & Clayton & 7.74 & 49.36 & -96.72 & -95.05 \\
\hline & Frank & 25.62 & 51.88 & -101.76 & -100.10 \\
\hline \multirow{5}{*}{ Kota Tinggi } & Joe & 5.57 & 36.72 & -71.43 & -69.77 \\
\hline & Gumbel & 5.22 & 46.32 & -90.64 & -88.98 \\
\hline & Gaussian & 0.95 & 50.27 & -98.55 & -96.76 \\
\hline & Clayton & 4.53 & 39.76 & -77.52 & -75.73 \\
\hline & Frank* & 20.30 & 50.42 & -98.84 & -97.05 \\
\hline \multirow{5}{*}{ Sembrong } & Joe & 4.79 & 37.22 & -72.44 & -70.66 \\
\hline & Gumbel & 4.26 & 45.16 & -88.33 & -86.54 \\
\hline & Gaussian & 0.96 & 53.70 & -105.40 & -103.61 \\
\hline & Clayton* & 7.70 & 56.74 & -111.48 & -109.69 \\
\hline & Frank & 22.73 & 54.51 & -107.01 & -105.23 \\
\hline \multirow{5}{*}{ Ladang Lambak } & Joe & 4.37 & 33.72 & -65.45 & -63.66 \\
\hline & Gumbel & 4.30 & 44.43 & -86.86 & -85.07 \\
\hline & Gaussian* & 0.94 & 52.08 & -102.16 & -100.29 \\
\hline & Clayton & 4.84 & 41.70 & -81.39 & -79.52 \\
\hline & Frank & 15.85 & 45.64 & -89.28 & -87.41 \\
\hline
\end{tabular}


8 of 21

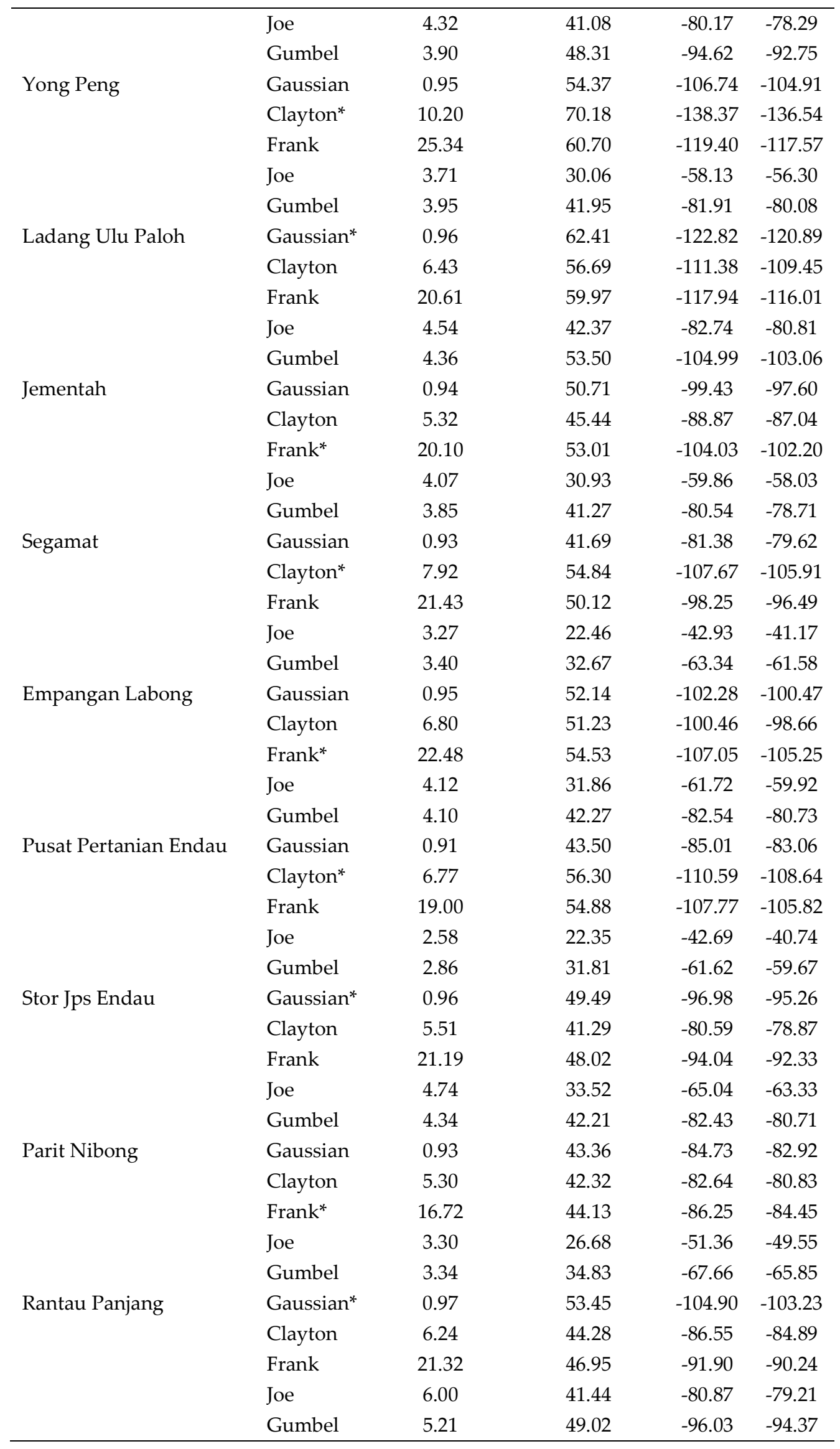


9 of 21

\begin{tabular}{|c|c|c|c|c|c|}
\hline \multirow[t]{5}{*}{ Jeniang } & Gaussian & 0.95 & 60.33 & -118.66 & -116.69 \\
\hline & Clayton* & 10.68 & 79.67 & -157.35 & -155.37 \\
\hline & Frank & 28.22 & 73.50 & -145.01 & -143.04 \\
\hline & Joe & 4.05 & 35.68 & -69.36 & -67.39 \\
\hline & Gumbel & 4.23 & 50.01 & -98.02 & -96.05 \\
\hline \multirow[t]{5}{*}{ Telok Rimba } & Gaussian* & 0.96 & 57.49 & -112.98 & -111.17 \\
\hline & Clayton & 6.77 & 51.61 & -101.23 & -99.42 \\
\hline & Frank & 21.53 & 54.61 & -107.21 & -105.41 \\
\hline & Joe & 4.63 & 37.93 & -73.86 & -72.06 \\
\hline & Gumbel & 4.45 & 48.27 & -94.55 & -92.74 \\
\hline \multirow[t]{5}{*}{ Jasin } & Gaussian* & 0.97 & 61.71 & -121.41 & -119.65 \\
\hline & Clayton & 7.37 & 52.22 & -102.44 & -100.68 \\
\hline & Frank & 27.02 & 59.31 & -116.61 & -114.85 \\
\hline & Joe & 5.28 & 38.67 & -75.34 & -73.58 \\
\hline & Gumbel & 5.01 & 49.95 & -97.91 & -96.14 \\
\hline \multirow[t]{5}{*}{ Jalan Empat } & Gaussian* & 0.98 & 59.01 & -116.03 & -114.44 \\
\hline & Clayton & 11.32 & 53.61 & -105.22 & -103.63 \\
\hline & Frank & 35.11 & 56.64 & -111.27 & -109.69 \\
\hline & Joe & 9.29 & 49.86 & -97.71 & -96.13 \\
\hline & Gumbel & 7.84 & 58.06 & -114.12 & -112.54 \\
\hline \multirow[t]{5}{*}{ Ladang Bukit Bertam } & Gaussian* & 0.96 & 56.57 & -111.14 & -109.36 \\
\hline & Clayton & 6.74 & 49.59 & -97.19 & -95.40 \\
\hline & Frank & 22.09 & 53.78 & -105.56 & -103.77 \\
\hline & Joe & 5.01 & 37.57 & -73.14 & -71.36 \\
\hline & Gumbel & 4.58 & 47.79 & -93.57 & -91.79 \\
\hline \multirow[t]{5}{*}{ Batu Kurau } & Gaussian & 0.95 & 47.38 & -92.75 & -90.97 \\
\hline & Clayton & 5.37 & 42.41 & -82.83 & -81.04 \\
\hline & Frank $^{*}$ & 19.25 & 48.53 & -95.07 & -93.28 \\
\hline & Joe & 3.93 & 29.77 & -57.53 & -55.75 \\
\hline & Gumbel & 3.80 & 38.81 & -75.63 & -73.84 \\
\hline \multirow[t]{5}{*}{ Ladang Sepang } & Gaussian* & 0.96 & 62.15 & -122.30 & -120.37 \\
\hline & Clayton & 5.37 & 51.64 & -101.28 & -99.35 \\
\hline & Frank & 21.92 & 61.87 & -121.75 & -119.82 \\
\hline & Joe & 5.28 & 46.07 & -90.14 & -88.21 \\
\hline & Gumbel & 4.67 & 56.31 & -110.63 & -108.70 \\
\hline \multirow[t]{5}{*}{ Sungai Mangg } & Gaussian & 0.96 & 45.96 & -89.92 & -88.25 \\
\hline & Clayton & 6.45 & 43.43 & -84.86 & -83.19 \\
\hline & Frank $^{*}$ & 21.46 & 46.96 & -91.91 & -90.25 \\
\hline & Joe & 4.80 & 30.29 & -58.57 & -56.91 \\
\hline & Gumbel & 4.43 & 39.39 & -76.79 & -75.12 \\
\hline \multirow[t]{5}{*}{ Ladang Bukit Kerayong } & Gaussian & 0.95 & 42.93 & -83.86 & -82.25 \\
\hline & Clayton* & 9.51 & 51.51 & -101.03 & -99.42 \\
\hline & Frank & 26.03 & 48.58 & -95.16 & -93.55 \\
\hline & Joe & 4.32 & 26.69 & -51.38 & -49.77 \\
\hline & Gumbel & 4.43 & 36.35 & -70.69 & -69.08 \\
\hline \multirow[t]{2}{*}{ Ladang Tuan Mee } & Gaussian & 0.86 & 23.34 & -44.68 & -43.10 \\
\hline & Clayton* & 5.17 & 32.04 & -62.09 & -60.50 \\
\hline
\end{tabular}


10 of 21

\begin{tabular}{|c|c|c|c|c|c|}
\hline & Frank & 14.25 & 29.53 & -57.05 & -55.47 \\
\hline & Joe & 3.45 & 20.00 & -37.99 & -36.41 \\
\hline & Gumbel & 3.25 & 26.13 & -50.26 & -48.67 \\
\hline \multirow[t]{5}{*}{ Tanjung Karang } & Gaussian* & 0.97 & 64.27 & -126.55 & -124.76 \\
\hline & Clayton & 6.07 & 47.89 & -93.79 & -92.00 \\
\hline & Frank & 24.79 & 58.48 & -114.96 & -113.17 \\
\hline & Joe & 7.59 & 53.08 & -104.16 & -102.37 \\
\hline & Gumbel & 6.06 & 61.11 & -120.22 & -118.44 \\
\hline \multirow[t]{5}{*}{ Sungai Bernam } & Gaussian & 0.94 & 52.76 & -103.52 & -101.59 \\
\hline & Clayton & 5.09 & 48.75 & -95.50 & -93.56 \\
\hline & Frank* & 20.26 & 58.21 & -114.43 & -112.50 \\
\hline & Joe & 3.51 & 30.14 & -58.28 & -56.35 \\
\hline & Gumbel & 3.45 & 40.82 & -79.65 & -77.72 \\
\hline \multicolumn{6}{|c|}{ Table A2. Goodness of Fit tests for CML } \\
\hline Station & Copula & Estimate $\theta$ & $\begin{array}{c}\text { Maximum } \\
\text { Likelihood }\end{array}$ & AIC & BIC \\
\hline \multirow[t]{5}{*}{ Meranti } & Gaussian & 0.91 & 41.27 & -80.55 & -78.64 \\
\hline & Clayton & 2.47 & 21.52 & -41.04 & -39.13 \\
\hline & Frank & 15.72 & 46.71 & -91.41 & -89.50 \\
\hline & $\mathrm{Joe}^{*}$ & 6.49 & 51.61 & -101.23 & -99.32 \\
\hline & Gumbel & 4.27 & 49.74 & -97.48 & -95.57 \\
\hline \multirow[t]{5}{*}{ Kuala Jambu } & Gaussian & 0.90 & 30.80 & -59.61 & -57.90 \\
\hline & Clayton & 2.19 & 14.80 & -27.60 & -25.88 \\
\hline & Frank & 14.41 & 34.80 & -67.60 & -65.88 \\
\hline & $\mathrm{Joe}^{*}$ & 6.94 & 43.76 & -85.53 & -83.81 \\
\hline & Gumbel & 4.20 & 39.37 & -76.74 & -75.03 \\
\hline \multirow[t]{5}{*}{ Stesen Keretapi Tumpat } & Gaussian & 0.92 & 40.63 & -79.26 & -77.41 \\
\hline & Clayton & 2.77 & 23.23 & -44.46 & -42.61 \\
\hline & Frank* & 16.96 & 46.74 & -91.49 & -89.64 \\
\hline & Joe & 5.35 & 40.71 & -79.42 & -77.57 \\
\hline & Gumbel & 3.99 & 43.53 & -85.06 & -83.21 \\
\hline \multirow[t]{5}{*}{ Kampung Ibok } & Gaussian & 0.89 & 32.02 & -62.04 & -60.21 \\
\hline & Clayton & 2.02 & 14.67 & -27.33 & -25.50 \\
\hline & Frank & 13.18 & 35.83 & -69.67 & -67.84 \\
\hline & $\mathrm{Joe}^{*}$ & 6.84 & 48.26 & -94.52 & -92.69 \\
\hline & Gumbel & 4.03 & 42.08 & -82.17 & -80.34 \\
\hline \multirow[t]{5}{*}{ Dungun } & Gaussian & 0.90 & 36.51 & -71.02 & -69.13 \\
\hline & Clayton & 2.45 & 21.09 & -40.18 & -38.29 \\
\hline & Frank* & 13.81 & 40.33 & -78.67 & -76.77 \\
\hline & Joe & 4.83 & 37.90 & -73.79 & -71.90 \\
\hline & Gumbel & 3.57 & 39.71 & -77.42 & -75.53 \\
\hline \multirow[t]{5}{*}{ Kuala Brang } & Gaussian & 0.92 & 36.30 & -70.59 & -68.85 \\
\hline & Clayton & 3.12 & 24.04 & -46.09 & -44.35 \\
\hline & Frank* & 15.31 & 38.86 & -75.73 & -73.99 \\
\hline & Joe & 4.91 & 33.13 & -64.26 & -62.52 \\
\hline & Gumbel & 3.83 & 37.28 & -72.55 & -70.81 \\
\hline
\end{tabular}


11 of 21

\begin{tabular}{|c|c|c|c|c|c|}
\hline \multirow[t]{5}{*}{ Kuala Telemong } & Gaussian & 0.87 & 34.36 & -66.71 & -64.74 \\
\hline & Clayton & 2.18 & 19.34 & -36.69 & -34.72 \\
\hline & Frank* & 13.25 & 41.84 & -81.67 & -79.70 \\
\hline & Joe & 3.70 & 30.52 & -59.05 & -57.08 \\
\hline & Gumbel & 3.00 & 34.39 & -66.77 & -64.80 \\
\hline \multirow[t]{5}{*}{ Marang } & Gaussian & 0.88 & 37.16 & -72.31 & -70.32 \\
\hline & Clayton & 2.35 & 22.06 & -42.13 & -40.14 \\
\hline & Frank ${ }^{*}$ & 13.32 & 43.29 & -84.58 & -82.59 \\
\hline & Joe & 3.86 & 33.45 & -64.90 & -62.91 \\
\hline & Gumbel & 3.12 & 37.67 & -73.34 & -71.35 \\
\hline \multirow[t]{5}{*}{ Kuala Terengganu } & Gaussian & 0.85 & 28.32 & -54.64 & -52.73 \\
\hline & Clayton & 2.17 & 18.17 & -34.34 & -32.42 \\
\hline & Frank ${ }^{*}$ & 12.62 & 37.14 & -72.28 & -70.37 \\
\hline & Joe & 3.23 & 23.07 & -44.15 & -42.24 \\
\hline & Gumbel & 2.75 & 27.54 & -53.08 & -51.16 \\
\hline \multirow[t]{5}{*}{ Kampung Rahmat } & Gaussian & 0.89 & 36.33 & -70.66 & -68.74 \\
\hline & Clayton & 2.42 & 21.10 & -40.20 & -38.29 \\
\hline & Frank ${ }^{*}$ & 14.00 & 41.82 & -81.63 & -79.72 \\
\hline & Joe & 4.42 & 35.76 & -69.52 & -67.60 \\
\hline & Gumbel & 3.41 & 38.71 & -75.42 & -73.51 \\
\hline \multirow[t]{5}{*}{ Banggol } & Gaussian & 0.90 & 34.30 & -66.59 & -64.78 \\
\hline & Clayton & 2.33 & 17.87 & -33.75 & -31.94 \\
\hline & Frank & 14.55 & 38.83 & -75.67 & -73.86 \\
\hline & Joe $^{*}$ & 6.10 & 42.92 & -83.85 & -82.04 \\
\hline & Gumbel & 4.01 & 41.26 & -80.52 & -78.72 \\
\hline \multirow[t]{5}{*}{ Setiu } & Gaussian & 0.88 & 34.71 & -67.42 & -65.45 \\
\hline & Clayton & 2.27 & 20.78 & -39.57 & -37.59 \\
\hline & Frank ${ }^{*}$ & 11.87 & 37.89 & -73.78 & -71.81 \\
\hline & Joe & 3.83 & 32.45 & -62.90 & -60.93 \\
\hline & Gumbel & 3.05 & 35.60 & -69.19 & -67.22 \\
\hline \multirow[t]{5}{*}{ Pelangi Kampung Jawi 2} & Gaussian & 0.92 & 36.44 & -70.89 & -69.17 \\
\hline & Clayton & 2.70 & 19.42 & -36.84 & -35.13 \\
\hline & Frank & 17.84 & 42.34 & -82.68 & -80.97 \\
\hline & $\mathrm{Joe}^{*}$ & 7.04 & 44.94 & -87.87 & -86.16 \\
\hline & Gumbel & 4.63 & 43.70 & -85.40 & -83.69 \\
\hline \multirow[t]{5}{*}{ Bentong } & Gaussian & 0.91 & 27.97 & -53.94 & -52.42 \\
\hline & Clayton & 2.39 & 13.92 & -25.85 & -24.32 \\
\hline & Frank & 16.25 & 32.14 & -62.27 & -60.74 \\
\hline & Joe $^{*}$ & 8.53 & 41.62 & -81.23 & -79.71 \\
\hline & Gumbel & 4.78 & 36.40 & -70.80 & -69.27 \\
\hline \multirow[t]{5}{*}{ Paya Membang } & Gaussian & 0.89 & 34.45 & -66.90 & -65.03 \\
\hline & Clayton & 2.27 & 18.55 & -35.09 & -33.22 \\
\hline & Frank ${ }^{*}$ & 13.60 & 39.05 & -76.10 & -74.22 \\
\hline & Joe & 4.47 & 35.13 & -68.26 & -66.39 \\
\hline & Gumbel & 3.38 & 37.06 & -72.12 & -70.25 \\
\hline \multirow[t]{2}{*}{ Kampung Serambi } & Gaussian & 0.92 & 44.59 & -87.18 & -85.24 \\
\hline & Clayton & 2.90 & 26.35 & -50.70 & -48.76 \\
\hline
\end{tabular}


12 of 21

\begin{tabular}{|c|c|c|c|c|c|}
\hline \multirow{7}{*}{ Kerdau } & Frank* & 17.78 & 52.91 & -103.81 & -101.88 \\
\hline & Joe & 5.29 & 42.59 & -83.19 & -81.25 \\
\hline & Gumbel & 4.01 & 46.75 & -91.49 & -89.56 \\
\hline & Gaussian & 0.92 & 35.36 & -68.73 & -66.99 \\
\hline & Clayton & 2.58 & 18.94 & -35.88 & -34.15 \\
\hline & Frank* & 16.83 & 41.33 & -80.67 & -78.93 \\
\hline & Joe & 6.08 & 40.44 & -78.89 & -77.15 \\
\hline \multirow{4}{*}{ Sanggang } & Gumbel & 4.21 & 40.65 & -79.30 & -77.56 \\
\hline & Gaussian & 0.92 & 39.93 & -77.86 & -76.01 \\
\hline & Clayton & 2.69 & 22.41 & -42.83 & -40.98 \\
\hline & Frank* & 16.67 & 46.32 & -90.64 & -88.79 \\
\hline \multirow{6}{*}{ Pekan } & Joe & 5.53 & 41.95 & -81.90 & -80.05 \\
\hline & Gumbel & 4.02 & 44.01 & -86.02 & -84.17 \\
\hline & Gaussian & 0.87 & 29.32 & -56.63 & -54.76 \\
\hline & Clayton & 1.82 & 13.04 & -24.08 & -22.21 \\
\hline & Frank & 11.45 & 32.30 & -62.61 & -60.73 \\
\hline & Joe $^{*}$ & 5.19 & 40.09 & -78.17 & -76.30 \\
\hline \multirow{3}{*}{ Penor } & Gumbel & 3.42 & 36.83 & -71.65 & -69.78 \\
\hline & Gaussian & 0.88 & 31.89 & -61.77 & -59.92 \\
\hline & Clayton & 2.18 & 17.02 & -32.05 & -30.20 \\
\hline \multirow{7}{*}{ Kuala Krau } & Frank* & 13.31 & 37.11 & -72.22 & -70.37 \\
\hline & Joe & 4.07 & 30.79 & -59.59 & -57.74 \\
\hline & Gumbel & 3.16 & 33.22 & -64.43 & -62.58 \\
\hline & Gaussian & 0.90 & 37.61 & -73.21 & -71.28 \\
\hline & Clayton & 2.23 & 19.08 & -36.16 & -34.22 \\
\hline & Frank & 14.27 & 42.99 & -83.98 & -82.05 \\
\hline & Joe $^{*}$ & 5.56 & 45.67 & -89.34 & -87.41 \\
\hline \multirow{3}{*}{ Paya Kangsar } & Gumbel & 3.80 & 44.62 & -87.24 & -85.31 \\
\hline & Gaussian & 0.90 & 32.93 & -63.85 & -62.09 \\
\hline & Clayton & 2.22 & 15.90 & -29.81 & -28.04 \\
\hline \multirow{7}{*}{ Ladang Kuala Reman } & Frank & 14.45 & 36.51 & -71.03 & -69.27 \\
\hline & Joe $^{*}$ & 7.22 & 47.35 & -92.70 & -90.94 \\
\hline & Gumbel & 4.29 & 42.07 & -82.15 & -80.39 \\
\hline & Gaussian & 0.90 & 30.13 & -58.26 & -56.57 \\
\hline & Clayton & 2.18 & 14.35 & -26.69 & -25.00 \\
\hline & Frank & 14.18 & 33.29 & -64.57 & -62.88 \\
\hline & Joe $^{*}$ & 7.38 & 44.65 & -87.30 & -85.61 \\
\hline \multirow{3}{*}{ Kuala Lipis } & Gumbel & 4.29 & 39.01 & -76.02 & -74.33 \\
\hline & Gaussian & 0.93 & 35.04 & -68.08 & -66.42 \\
\hline & Clayton & 2.62 & 17.87 & -33.74 & -32.08 \\
\hline \multirow{7}{*}{ Kota Tinggi } & Frank & 19.24 & 42.01 & -82.02 & -80.35 \\
\hline & Joe $^{*}$ & 8.90 & 49.64 & -97.29 & -95.63 \\
\hline & Gumbel & 5.18 & 44.88 & -87.76 & -86.09 \\
\hline & Gaussian & 0.89 & 31.74 & -61.48 & -59.70 \\
\hline & Clayton & 2.34 & 17.67 & -33.34 & -31.55 \\
\hline & Frank* & 14.57 & 37.62 & -73.23 & -71.45 \\
\hline & Joe & 4.67 & 32.46 & -62.93 & -61.15 \\
\hline
\end{tabular}




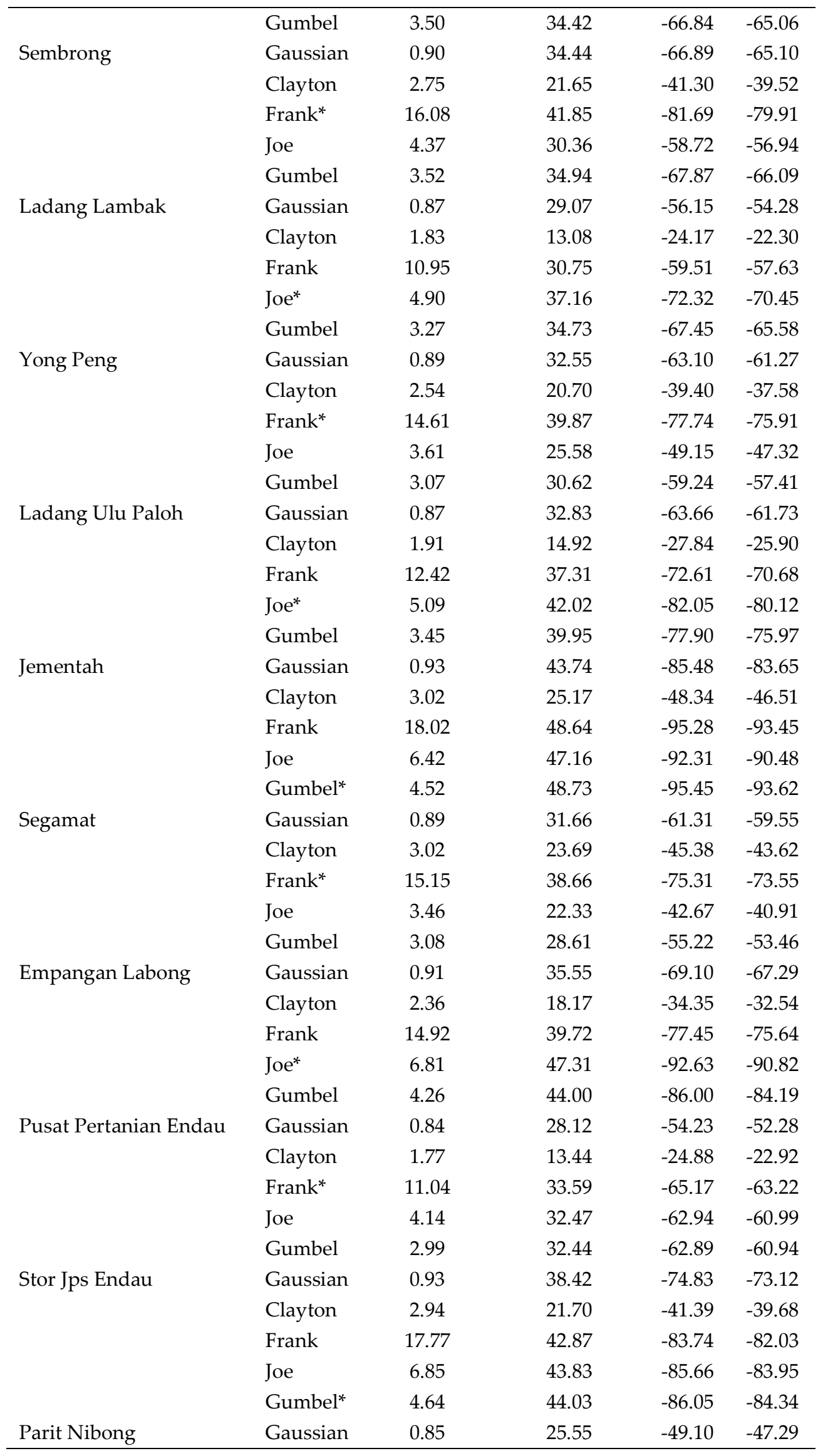




\begin{tabular}{|c|c|c|c|c|c|}
\hline & Clayton & 1.76 & 11.59 & -21.19 & -19.38 \\
\hline & Frank & 10.85 & 28.68 & -55.35 & -53.55 \\
\hline \multirow{5}{*}{ Rantau Panjang } & Joe $^{*}$ & 4.15 & 29.65 & -57.30 & -55.50 \\
\hline & Gumbel & 3.00 & 29.31 & -56.61 & -54.81 \\
\hline & Gaussian & 0.92 & 34.72 & -67.44 & -65.78 \\
\hline & Clayton & 2.71 & 18.84 & -35.69 & -34.02 \\
\hline & Frank & 16.94 & 38.94 & -75.87 & -74.21 \\
\hline \multirow{5}{*}{ Jeniang } & Joe $^{*}$ & 7.26 & 43.42 & -84.84 & -83.18 \\
\hline & Gumbel & 4.65 & 41.67 & -81.34 & -79.67 \\
\hline & Gaussian & 0.89 & 36.91 & -71.82 & -69.85 \\
\hline & Clayton & 2.46 & 22.79 & -43.57 & -41.60 \\
\hline & Frank* & 14.77 & 46.24 & -90.48 & -88.51 \\
\hline \multirow{5}{*}{ Telok Rimba } & Joe & 4.25 & 34.96 & -67.91 & -65.94 \\
\hline & Gumbel & 3.37 & 39.18 & -76.36 & -74.39 \\
\hline & Gaussian & 0.90 & 34.03 & -66.07 & -64.26 \\
\hline & Clayton & 2.17 & 16.07 & -30.14 & -28.33 \\
\hline & Frank & 14.68 & 38.73 & -75.46 & -73.65 \\
\hline \multirow{5}{*}{ Jasin } & Joe $^{*}$ & 7.49 & 51.42 & -100.84 & -99.03 \\
\hline & Gumbel & 4.39 & 44.93 & -87.87 & -86.06 \\
\hline & Gaussian & 0.91 & 34.54 & -67.08 & -65.32 \\
\hline & Clayton & 2.41 & 17.92 & -33.83 & -32.07 \\
\hline & Frank & 15.06 & 38.34 & -74.69 & -72.93 \\
\hline \multirow{5}{*}{ Jalan Empat } & Joe $^{*}$ & 6.37 & 42.93 & -83.86 & -82.10 \\
\hline & Gumbel & 4.16 & 41.01 & -80.02 & -78.26 \\
\hline & Gaussian & 0.94 & 34.95 & -67.90 & -66.31 \\
\hline & Clayton & 3.06 & 19.68 & -37.35 & -35.77 \\
\hline & Frank* & 19.96 & 40.57 & -79.14 & -77.55 \\
\hline \multirow{5}{*}{ Ladang Bukit Bertam } & Joe & 6.78 & 37.97 & -73.94 & -72.36 \\
\hline & Gumbel & 4.69 & 38.99 & -75.98 & -74.39 \\
\hline & Gaussian & 0.93 & 40.10 & -78.21 & -76.42 \\
\hline & Clayton & 3.04 & 24.23 & -46.46 & -44.67 \\
\hline & Frank & 16.18 & 42.69 & -83.38 & -81.59 \\
\hline \multirow{5}{*}{ Batu Kurau } & Joe & 5.88 & 41.62 & -81.24 & -79.45 \\
\hline & Gumbel* & 4.27 & 43.75 & -85.51 & -83.73 \\
\hline & Gaussian & 0.89 & 30.47 & -58.93 & -57.15 \\
\hline & Clayton & 2.17 & 15.84 & -29.68 & -27.89 \\
\hline & Frank* & 13.46 & 35.50 & -69.01 & -67.22 \\
\hline \multirow{5}{*}{ Ladang Sepang } & Joe & 4.59 & 31.82 & -61.65 & -59.86 \\
\hline & Gumbel & 3.37 & 33.05 & -64.10 & -62.32 \\
\hline & Gaussian & 0.90 & 38.59 & -75.19 & -73.26 \\
\hline & Clayton & 2.48 & 22.03 & -42.05 & -40.12 \\
\hline & Frank* & 14.89 & 45.62 & -89.23 & -87.30 \\
\hline \multirow{5}{*}{ Sungai Mangg } & Joe & 4.46 & 35.94 & -69.88 & -67.95 \\
\hline & Gumbel & 3.45 & 39.67 & -77.34 & -75.41 \\
\hline & Gaussian & 0.94 & 40.45 & -78.90 & -77.24 \\
\hline & Clayton & 3.32 & 23.55 & -45.09 & -43.43 \\
\hline & Frank & 18.99 & 43.33 & -84.66 & -82.99 \\
\hline
\end{tabular}




\begin{tabular}{llcccc}
\hline \multirow{4}{*}{ Ladang Bukit Kerayong } & Joe & 7.41 & 44.77 & -87.53 & -85.87 \\
& Gumbel $^{*}$ & 5.02 & 45.43 & -88.85 & -87.19 \\
& Gaussian & 0.91 & 30.37 & -58.75 & -57.14 \\
& Clayton & 2.57 & 16.63 & -31.27 & -29.66 \\
& Frank* & 16.66 & 35.68 & -69.36 & -67.75 \\
& Joe & 6.02 & 35.28 & -68.56 & -66.95 \\
Ladang Tuan Mee & Gumbel & 4.18 & 35.52 & -69.03 & -67.42 \\
& Gaussian & 0.87 & 23.04 & -44.08 & -42.50 \\
& Clayton & 2.77 & 17.42 & -32.84 & -31.25 \\
Tanjung Karang & Frank & 14.27 & 29.08 & -56.17 & -54.59 \\
& Joe & 4.84 & 27.20 & -52.41 & -50.82 \\
& Gumbel* & 3.74 & 29.65 & -57.29 & -55.71 \\
& Gaussian & 0.92 & 37.60 & -73.20 & -71.41 \\
& Clayton & 2.47 & 18.79 & -35.58 & -33.79 \\
& Frank & 16.95 & 43.17 & -84.34 & -82.56 \\
& Joe* & 8.81 & 56.25 & -110.50 & -108.72 \\
& Gumbel & 4.98 & 49.25 & -96.50 & -94.71 \\
& Gaussian & 0.90 & 37.68 & -73.36 & -71.43 \\
& Clayton & 2.44 & 21.70 & -41.39 & -39.46 \\
& Frank* & 14.68 & 44.64 & -87.28 & -85.35 \\
& Joe & 4.02 & 32.65 & -63.31 & -61.38 \\
& Gumbel & 3.24 & 37.04 & -72.08 & -70.15 \\
\hline
\end{tabular}

\section{References}

1. Department of Irrigation and Drainage Malaysia. Flood Management - Programme and Activities: https://www.water.gov.my/index.php/pages/view/419?mid=244 (12 November 2017).

2. Renard, B.; Lang, M. Use of a Gaussian copula for multivariate extreme value analysis: Some case studies in hydrology. Advances in Water Resources 2007, 30(4), 897-912.

3. Zhang, L.; Singh, V.P. Bivariate rainfall frequency distributions using Archimedean copulas. Journal of Hydrology 2007, 332(1-2), 93-109.

4. Abdul Rauf, U.F.; Zeephongsekul, P. Modelling rainfall severity and duration in north-eastern Victoria using Copulas. 19th International Congress on Modelling and Simulation, Perth, Australia, 12-16 December 2011, 3462-3468.

5. Daneshkhah, A.; Remesan, R.; Chatrabgoun, O.; Holman, I.P. Probabilistic modeling of flood characterizations with parametric and minimum information pair-copula model. Journal of Hydrology 2016, 540, 469-487.

6. Ozga-Zielinski, B; Ciupak, M.; Adamowski, J.; Khalil, B.; Malard, J. Snow-melt flood frequency analysis by means of copula based 2D probability distributions for the Narew River in Poland. Journal of Hydrology: Regional Studies 2016, 6, 26-51.

7. Sklar, A. Fonctions de répartition à $\mathrm{n}$ dimensions et leurs marges. Publ. Inst. Statist. Univ. Paris 1959, 8 , 229-231.

8. Chen, L.; Singh, V.P.; Guo, S.; Zhou, J.; Zhang, J. Copula-based method for multisite monthly and daily streamflow simulation. Journal of Hydrology 2015, 528, 369-384.

9. Genest, C.; Favre, A.C. Everything You Always Wanted to Know about Copula Modeling but Were Afraid to Ask. Journal of Hydrologic Engineering 2007, 12(4), 347-368.

10. Masina, M.; Lamberti, A.; Archetti, R. Coastal flooding: A copula based approach for estimating the joint probability of water levels and waves. Coastal Engineering 2015, 97, 37-52.

11. Tosunoglu, F.; Kisi, O. Joint modelling of annual maximum drought severity and corresponding duration. Journal of Hydrology 2016, 543, 406-422.

12. Wan Zin, W.Z.; Ibrahim, K.; Jemain, A.A. Evaluating the dry conditions in Peninsular Malaysia using bivariate copula. ANZIAM J 2010, 51, 555-569. 
13. Shiau, J.T. Fitting drought duration and severity with two-dimensional copulas. Water Resources Management 2006, 20(5), 795-815.

14. Genest, C.; Favre, A.C.; Béliveau, J.; Jacques, C. Metaelliptical copulas and their use in frequency analysis of multivariate hydrological data. Water Resources Research 2007, 43(9), 1-12.

15. Genest, C.; Rémillard, B.; Beaudoin, D. Goodness-of-fit tests for copulas: A review and a power study. Insurance: Mathematics and Economics 2009, 44(2), 199-213.

16. Hao, Z.; AghaKouchak, A. A Nonparametric Multivariate Multi-Index Drought Monitoring Framework. Journal of Hydrometeorology 2014, 15(1), 89-101.

17. Salvadori, G.; De Michele, C.; Kottegoda, N.T.; Rosso, R. Extremes in Nature: An Approach Using Copulas. 1st ed.; Springer: Netherlands, 2007; pp. 1-292, 9781402044151.

18. Joe, H. Multivariate Models and Multivariate Dependence Concepts. Chapman and Hall: London, 1997; pp. 1-424, 9780412073311.

19. Nelsen, R.B. An Introduction to Copulas, 2nd ed.; Springer: New York, 2006; pp. 1-272, 9780387286785

20. Trivedi, P.K; Zimmer, D.M. Copula modeling: An introduction for practitioners. Foundations and Trends Econometrics 2007, 1(1), 1-111.

21. Kelly, K.S.; Krzysztofowicz, R. A bivariate meta-Gaussian density for use in hydrology. Stochastic Hydrology and Hydraulics 1997, 11(1), 17-31.

22. Shiau, J.T.; Feng, S.; Nadarajah, S. Assessment of hydrological droughts for the Yellow River, China, using copulas. Hydrological Processes 2007, 21(16), 2157-2163.

23. Wong, G.; Lambert, M.F.; Metcalfe, A.V. Trivariate copulas for characterisation of droughts. ANZIAM J 2008, 49, C306-C323.

24. Favre, A.C.; El Adlouni, S.; Perreault, L.; Thiémonge, N.; Bobée, B. Multivariate hydrological frequency analysis using copulas. Water Resources Research 2004, 40(1), 1-12.

25. Mckee, T.B.; Doesken, N.J.; Kleist, J. The Relationship Of Drought Frequency And Duration To Time Scales. Eighth Conference on Applied Climatology, Anaheim, California, 17-22 January 1993; 179-184.

26. Jemain, A.A.; Mohd Deni, S.; Syed Jamaludin, S.S.; Wan Zin, W.Z. Penyurihan Ikhtisar Data Hujan, 1st ed.; Dewan Bahasa dan Pustaka: Kuala Lumpur, Malaysia, 2015; pp. 1-213, 9789834619299

27. Porth, L.S.; Boes, D.C.; Davis, R.A.; Troendle, C.A.; King, R.M. Development of a Technique to Determine Adequate Sample Size Using Subsampling and Return Interval Estimation. Journal of Hydrology 2001, 251(1-2), 110-116.

28. Department of Irrigation and Drainage Malaysia. Updating of Condition of Flooding in Malaysia. National Register of River Basins 2003, Vol. 2, 1-209.

29. Guttman, N.B. Accepting the Standardized Precipitation Index: A Calculation Algorithm. JAWRA Journal of the American Water Resources Association 1999, 35(2), 311-322.

30. Boulanger, J.P.; Martinez, F.; Penalba, O.; Segura, E.C. Neural network based daily precipitation generator (NNGEN-P). Climate Dynamics 2007, 28(2-3), 307-324.

31. Demarta, S.; McNeil, A.J. The t Copula and Related Copulas. International Statistical Review 2005, 73(1), 111-129.

32. Genest, C.; Ghoudi, K.; Rivest, L.P. A semiparametric estimation procedure of dependence parameters in multivariate families of distributions. Biometrika 1995, 82(3), 543-552.

33. Genest, C.; Mackay, J. The Joy of Copulas: Bivariate Distributions with Uniform Marginals. American Statistician 1986, 40(4), 280-283. 